\title{
Initial NaCl-induced atmospheric corrosion of a dual-phase Cu60-40Zn alloy - Effect of UV illumination
}

\author{
Xiaoying Sun ${ }^{1,2}$, Zhuoyuan Chen ${ }^{1,2, *}$, Jiarun $\mathrm{Li}^{1}$, Jian Hou ${ }^{2}$ and Likun $\mathrm{Xu}^{2}$ \\ ${ }^{1}$ Key Laboratory of Marine Environmental Corrosion and Bio-fouling, Institute of Oceanology, \\ Chinese Academy of Sciences, 7 Nanhai Road, Qingdao 266071, China \\ ${ }^{2}$ State Key Laboratory for Marine Corrosion and Protection, Luoyang Ship Material Research \\ Institute, Wenhai Road, Qingdao 266237, China. \\ *E-mail: zychen@qdio.ac.cn
}

doi: $10.20964 / 2018.08 .71$

Received: 25 March 2018 / Accepted: 22 May 2018 / Published: 5 July 2018

\begin{abstract}
In this paper, the effect of ultraviolet (UV) illumination on the $\mathrm{NaCl}$-induced atmospheric corrosion of a Cu60-40Zn alloy was investigated. UV illumination affects the atmospheric corrosion of the Cu60$40 \mathrm{Zn}$ alloy in terms of corrosion rate, corrosion morphology and corrosion products. The $\mathrm{NaCl}$ induced atmospheric corrosion rate of the Cu60-40Zn alloy increases under UV illumination due to the increase of the corrosion initiation sites and the photovoltaic effect of the corrosion products. The increased photoinduced potential and the transfer of the photogenerated electrons from the substrate $\mathrm{Cu}-\mathrm{Zn}$ alloy to the corrosion products provide evidence for the accelerated anodic reactions under light illumination, and thus promote the atmospheric corrosion of the Cu60-40Zn alloy under UV illumination.
\end{abstract}

Keywords: $\mathrm{Cu}-\mathrm{Zn}$ alloy; atmospheric corrosion; UV illumination; $\mathrm{NaCl}$ particles; XPS

\section{FULL TEXT}

(C) 2018 The Authors. Published by ESG (www.electrochemsci.org). This article is an open access article distributed under the terms and conditions of the Creative Commons Attribution license (http://creativecommons.org/licenses/by/4.0/). 